\title{
How Different Cultures Affect Online Communication on Knowledge Sharing between the Thais and Chinese
}

\author{
Pimnapa Atsawintarangkun and Takaya Yuizono \\ Japan Advanced Institute of Science and Technology \\ 1-1 Asahidai, Nomi, Ishikawa 923-1211, Japan \\ \{pimnapa.a,yuizono\}@jaist.ac.jp
}

\begin{abstract}
In today's society, people can share knowledge with others via online communication tools. However, the process of sharing or acquiring knowledge between people from different cultures may involve problems and misunderstandings. To enhance intercultural competences and improve understandings of the cultural variations, this paper investigates how different cultures affect patterns of online knowledge sharing; the study focuses on Thais and Chinese who have a high-context communication style. We set up a laboratory experiment to analyze discourses posted by Thais and Chinese utilizing six categories including declaration, interrogation, exclamation, opinion, acknowledgement, and agreement. The discourse analysis showed that there is a significant difference in the number of interrogation and exclamation discourses. Then, we examined connections between the discourse analysis results and cultural dimensions conducted by Hofstede [6]. A post-questionnaire was provided to investigate participants' attitudes during online knowledge sharing. Our experiment revealed that the main cultural dimensions that influence Thais and Chinese to have the different patterns of online knowledge sharing are individualism, masculinity, and uncertainty avoidance. Moreover, problems with the online communication among people who have a high-context communication style are explained. It can be concluded that the cultural differences and the high-context communication style of the Thai and Chinese can influence the ways knowledge is shared between these groups online.
\end{abstract}

Keywords: intercultural communication, online communication, knowledge sharing, Thai and Chinese, discourse analysis, cultural dimensions, high-context communication.

\section{Introduction}

Knowledge sharing is a process of knowledge being exchanged among people. Knowledge can be defined as personalized information related to facts, skills, suggestions, procedures, concepts, interpretations, ideas, observations, and judgments that may or may not be unique, useful or accurate [1].

In the era of globalization, people can use online communication tools such as social media, online forums, and blogs to share knowledge with others. Therefore, usergenerated content is becoming a valuable source of knowledge. However, a process to 
share or acquire knowledge among people who come from different cultures may involve problems such as misunderstanding messages, linguistic problems, and negative feelings. Moreover, we can assume that online knowledge sharing among people who have a high-context style of communication will face problems since the highcontext style is often indirect, ambiguous, and uses nonverbal elements.

Previous works have focused on comparing behaviors between "Western" and "Eastern", comparing countries that are on opposite ends of the Hofstede scale and comparing user behaviors between high-context style and low-context style in the online community $[3,4,8,9,11,13]$. There are few works that investigate how different cultures affect patterns of online knowledge sharing among people who have the high-context communication style.

Thus, this paper aims to enhance understanding of the cultural variations by examining connections between cultural dimensions and online knowledge sharing patterns of users who have the high-context communication style. Thais and Chinese are selected because they have obvious cultural differences and their communication styles are considered to be high-context style [7,8].

The rest of this paper is organized as follows. In Section 2, some backgrounds and theories are described. Section 3 gives details of the methodology of the study. Our analysis results and discussions are presented in Section 4. Finally, Section 5 gives the conclusions and future directions.

\section{Backgrounds and Theories}

\subsection{Cultural Knowledge}

In this work, we focus on the online sharing of cultural knowledge between Chinese and Thais. Cultural knowledge is defined as the state of knowing about behavior, belief, value or practices that people who live in the same society use for living in that society. This type of knowledge can help individuals to become familiar with people from other cultures. It also can reduce miscommunication, conflict, and failure in intercultural communication [10]. To avoid failures in intercultural communication, cultural knowledge of a partner country is required [17]. Thus, two topics in this experiment are related to cultural knowledge of the Thai and Chinese. The first topic asks about metaphorical expressions in their cultures. For example, "Slow as a tortoise" is an expression found in Chinese culture and also recognized in Thai culture. Another example is "Thin as a monkey" in Chinese culture, but in Thai, they say, "Thin as a dry shrimp." The other topic asks about beliefs in daily life such as color and gift giving/taking. For instance, the color white has a negative connotation in China, but white represents pureness in Thailand.

\subsection{Cultural Dimensions}

Hofstede [6] has developed the most frequently cited model for such cultural measures called national cultural dimensions. This model provides a pragmatic, structured framework for studying culture [15]. First, Hofstede identified four inter-cultural dimensions including power distance, individualism, uncertainty avoidance, and masculinity. After that, Hofstede and Bond added the fifth dimension: long-term orientation. Definitions of five cultural dimensions are as follows: 
1. Power distance (PDI): the degree to which members of a society accept and expect that power is distributed unequally in particular society.

2. Individualism (IDV): the degree to which a society reinforces individual or collective achievement and interpersonal relationships.

3. Masculinity (MAS): the degree to which a society is dependent on achievement, assertiveness and competition (masculine characteristics) as opposed to femininity, which reflects how much a society values cooperation, relationships, and caring for others.

4. Uncertainty avoidance (UAI): the extent to which the members of a society feel uncomfortable with uncertainty and ambiguity.

5. Long-term orientation (LTO): the extent to which a society shows a pragmatic, future-oriented perspective rather than a conventional, historical, short-term point of view.

\subsection{Communication Styles}

Hall [5] has classified styles of communication based on a key factor: "context." It relates to the framework, background, and surrounding situations in which communication or an event happens. Based on Hall's theory, two communication styles were defined as low-context and high-context style. Low-context style, typically Western, is logical, linear, individualistic, and action-oriented. The actions that are characteristic of this style are often verbally explicit and straightforward. High-context style (typically of Eastern cultures) consists of communication with the following characteristics: indirect, formal, ambiguous, and respectful. The following table shows some of the characteristics of low-context style and high-context style.

Table 1. Characteristics of low-context style and high-context style [2]

\begin{tabular}{|c|c|}
\hline $\begin{array}{c}\text { Low-context style } \\
\end{array}$ & $\begin{array}{c}\text { High-context style } \\
\end{array}$ \\
\hline $\begin{array}{l}\text { Low use of nonverbal elements: mes- } \\
\text { sage is carried more by words than by } \\
\text { nonverbal means. }\end{array}$ & $\begin{array}{l}\text { High use of nonverbal elements such as } \\
\text { voice tone, facial expression, gestures, } \\
\text { and eye movement that carry significant } \\
\text { parts of conversation. }\end{array}$ \\
\hline $\begin{array}{l}\text { Verbal message is explicit. Context is } \\
\text { less important than words. }\end{array}$ & $\begin{array}{l}\text { Verbal message is implicit; context (situ- } \\
\text { ation, people, and nonverbal elements) is } \\
\text { more important than words. }\end{array}$ \\
\hline $\begin{array}{l}\text { Verbal message is direct; one spells } \\
\text { things out exactly. }\end{array}$ & $\begin{array}{l}\text { Verbal message is indirect; one talks } \\
\text { around the point and embellishes it. }\end{array}$ \\
\hline $\begin{array}{l}\text { Communication is seen as a way of } \\
\text { exchanging information, ideas, and } \\
\text { opinions. }\end{array}$ & $\begin{array}{l}\text { Communication is seen as an art form, a } \\
\text { way of engaging someone. }\end{array}$ \\
\hline $\begin{array}{l}\text { Disagreement is depersonalized. One } \\
\text { withdraws from conflict with another } \\
\text { and gets on with the task. Focus is on } \\
\text { rational solutions, not personal ones. } \\
\text { One can be explicit about another's } \\
\text { bothersome behavior. }\end{array}$ & $\begin{array}{l}\text { Disagreement is personalized. One is } \\
\text { sensitive to conflict expressed in anoth- } \\
\text { er's nonverbal communication. Conflict } \\
\text { must be resolved before work can } \\
\text { progress or must be avoided because it is } \\
\text { personally threatening. }\end{array}$ \\
\hline
\end{tabular}




\section{Methodology}

This study aims to determine what the main cultural dimensions are that influence users from different cultures (both with high-context style) to communicate differently when it comes to online knowledge sharing. In order to investigate connections between the cultural dimensions and knowledge sharing patterns, discussion discourses posted by participants were analyzed.

Participants in the laboratory experiment consisted of twelve Thais (Male $=8, \mathrm{Fe}-$ male $=4$ ) and twelve Chinese (Male $=7$, Female $=5$ ) ranging in age from 23 to 36 years $(M=26.92)$. They were studying at graduate school and all of them can use English fluently (average TOEIC score is 600).

\subsection{Experiment Procedure}

In this experiment, WordPress [16] (an open source web-based software program that used to build and maintain a website or blog) was provided to collect discussion samples from participants. Then, participants were randomly assigned into four groups

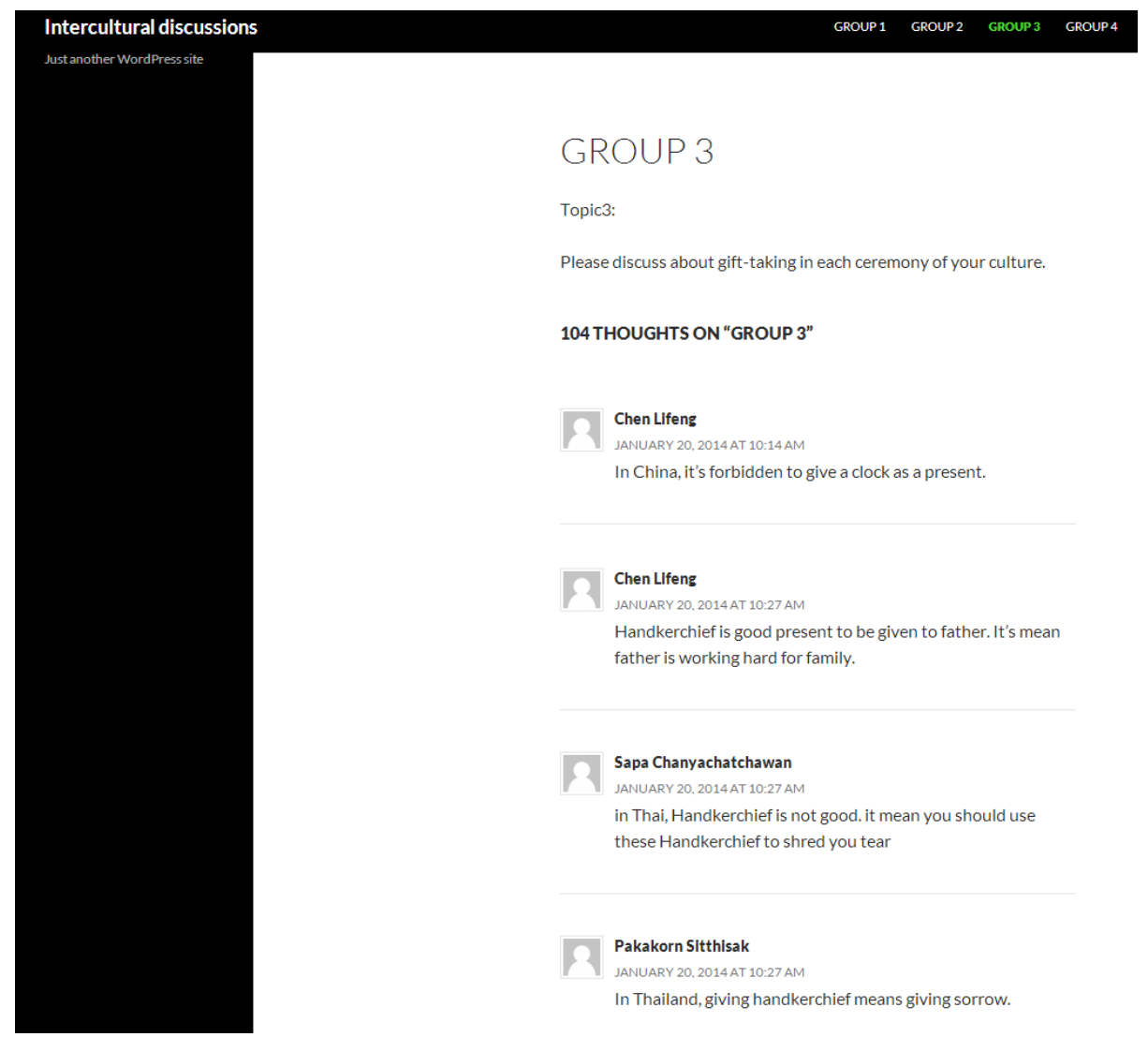

Fig. 1. Interface screen of online knowledge sharing 
consisting of three Thais and three Chinese. Each group was given 45 minutes to share and discuss the topics in their own styles. Participants were encouraged to share what they know, ask others to make mutual understandings and compare what are the differences and similarities. They were able to post any types of input such as pictures, emoticons or links, but English had to be the common language in the exchange. At the end, participants had 10 minutes to fill out a questionnaire. The interface screen of online knowledge sharing in this experiment is shown in Figure 1.

\subsection{Discourse Analysis}

The discourses posted by participants were retrieved from the database and the patterns of those discourses were analyzed by one author. The discourses can be classified into six classes:

1. Declaration: A phrase or a sentence of fact or knowledge that participants had shared in the online knowledge sharing.

Example: "In China, liquor is just one of the popular presents."

2. Interrogation: A phrase or a sentence of inquiry that asks for a reply.

Example: "In Thailand, do girls often wear white ornaments?"

3. Exclamation: A phrase or a sentence that expresses strong emotion or feeling and often contains an exclamatory mark.

Example: "Interesting!", “Oh.”

4. Opinion: A phrase or a sentence that shows opinion or comment of audience. Example: "I think Thais like white because of their religion.

5. Acknowledgement: A phrase or a sentence that acknowledges or recognizes another person or statement.

Example: "Yes.", "Thank you"

6. Agreement: A phrase or a sentence that expresses agreement between participants. Example: "I agree with you."

Then, we analyzed the connections between cultural dimensions and patterns of online knowledge sharing based on the six classes as mentioned above.

\section{$4 \quad$ Analysis Results and Discussions}

\subsection{Discourse Analysis Results}

For the discourse analysis, the number of discourses in each class and each nationality was counted as shown in Table 1 and Table 2. A percentage of each discourse class in Chinese and Thais was displayed in Table 3. Then, a nonparametric statistic test 
(Mann-Whitney U Test) was used for analyzing a significant difference between Chinese and Thais in the number of discourses in the six classes. The statistical result in Table 5 revealed significant difference in two classes including interrogation and exclamation. After that, a post-questionnaire was provided to support our analysis as shown in Table 6 by Mean, Standard Deviation and p-value. It investigates participants' attitudes toward the online knowledge-sharing experience. This questionnaire consists of seven questions, with responses varied on 1 (Very low) -5 (Very high) Likert scale.

Table 2. Number of discourses from Chinese participants

\begin{tabular}{|c|c|c|c|c|c|c|c|c|c|c|c|c|c|}
\hline \multirow{2}{*}{ Class } & \multicolumn{10}{|c|}{ Chinese participant No. } & \multirow{2}{*}{ Total } \\
\cline { 2 - 13 } & $\mathbf{1}$ & $\mathbf{2}$ & $\mathbf{3}$ & $\mathbf{4}$ & $\mathbf{5}$ & $\mathbf{6}$ & $\mathbf{7}$ & $\mathbf{8}$ & $\mathbf{9}$ & $\mathbf{1 0}$ & $\mathbf{1 1}$ & $\mathbf{1 2}$ & \\
\hline Declaration & 9 & 4 & 2 & 5 & 9 & 9 & 8 & 14 & 7 & 28 & 33 & 11 & $\mathbf{1 3 9}$ \\
\hline Interrogation & 0 & 0 & 0 & 0 & 1 & 3 & 5 & 2 & 1 & 0 & 4 & 1 & $\mathbf{1 7}$ \\
\hline Exclamation & 0 & 0 & 0 & 0 & 0 & 0 & 1 & 1 & 1 & 0 & 1 & 0 & $\mathbf{4}$ \\
\hline Opinion & 2 & 0 & 2 & 1 & 0 & 1 & 1 & 2 & 0 & 0 & 2 & 0 & $\mathbf{1 1}$ \\
\hline Acknowledgement & 1 & 1 & 1 & 0 & 1 & 2 & 0 & 2 & 0 & 1 & 0 & 1 & $\mathbf{1 0}$ \\
\hline Agreement & 2 & 0 & 0 & 0 & 0 & 1 & 2 & 0 & 0 & 0 & 0 & 0 & $\mathbf{5}$ \\
\hline Total & $\mathbf{1 4}$ & $\mathbf{5}$ & $\mathbf{5}$ & $\mathbf{6}$ & $\mathbf{1 1}$ & $\mathbf{1 6}$ & $\mathbf{1 7}$ & $\mathbf{2 1}$ & $\mathbf{9}$ & $\mathbf{2 9}$ & $\mathbf{4 0}$ & $\mathbf{1 3}$ & $\mathbf{1 8 6}$ \\
\hline
\end{tabular}

Table 3. Number of discourses from Thai participants

\begin{tabular}{|c|c|c|c|c|c|c|c|c|c|c|c|c|c|}
\hline \multirow{2}{*}{ Class } & \multicolumn{10}{|c|}{ Thai participant No. } & \multirow{2}{*}{ Total } \\
\cline { 2 - 14 } & $\mathbf{1}$ & $\mathbf{2}$ & $\mathbf{3}$ & $\mathbf{4}$ & $\mathbf{5}$ & $\mathbf{6}$ & $\mathbf{7}$ & $\mathbf{8}$ & $\mathbf{9}$ & $\mathbf{1 0}$ & $\mathbf{1 1}$ & $\mathbf{1 2}$ & \\
\hline Declaration & 9 & 6 & 14 & 5 & 4 & 6 & 16 & 3 & 4 & 13 & 19 & 2 & $\mathbf{1 0 1}$ \\
\hline Interrogation & 2 & 1 & 9 & 8 & 3 & 4 & 14 & 6 & 3 & 15 & 4 & 12 & $\mathbf{8 1}$ \\
\hline Exclamation & 5 & 1 & 2 & 1 & 2 & 1 & 1 & 3 & 0 & 1 & 1 & 4 & $\mathbf{2 2}$ \\
\hline Opinion & 4 & 3 & 4 & 1 & 1 & 0 & 0 & 1 & 2 & 0 & 2 & 2 & $\mathbf{2 0}$ \\
\hline Acknowledgement & 4 & 1 & 5 & 0 & 2 & 2 & 2 & 0 & 0 & 2 & 2 & 0 & $\mathbf{2 0}$ \\
\hline Agreement & 1 & 2 & 3 & 1 & 0 & 1 & 1 & 0 & 0 & 0 & 1 & 0 & $\mathbf{1 0}$ \\
\hline Total & $\mathbf{2 5}$ & $\mathbf{1 4}$ & $\mathbf{3 7}$ & $\mathbf{1 6}$ & $\mathbf{1 2}$ & $\mathbf{1 4}$ & $\mathbf{3 4}$ & $\mathbf{1 3}$ & $\mathbf{9}$ & $\mathbf{3 1}$ & $\mathbf{2 9}$ & $\mathbf{2 0}$ & $\mathbf{2 5 4}$ \\
\hline
\end{tabular}

Table 4. A percentage of discourses in Chinese and Thais

\begin{tabular}{|c|c|c|}
\hline Content classes & Chinese & Thai \\
\hline Declaration & $139(74.73 \%)$ & $101(39.76 \%)$ \\
\hline Interrogation & $17(9.14 \%)$ & $81(31.90 \%)$ \\
\hline Exclamation & $4(2.15 \%)$ & $22(8.66 \%)$ \\
\hline Opinion & $11(5.91 \%)$ & $20(7.87 \%)$ \\
\hline Acknowledgement & $10(5.38 \%)$ & $20(7.87 \%)$ \\
\hline Agreement & $5(2.69 \%)$ & $10(3.94 \%)$ \\
\hline Total & $186(100 \%)$ & $254(100 \%)$ \\
\hline
\end{tabular}


Table 5. Mean, Standard Deviation and p-value in each discourse class

\begin{tabular}{|c|c|c|c|}
\hline Content classes & Chinese & Thai & p-value \\
\hline Declaration & $11.58 \pm 9.44$ & $8.42 \pm 5.68$ & $\mathrm{n} . \mathrm{s}$ \\
\hline Interrogation & $1.42+1.73$ & $6.75 \pm 4.81$ & $<0.01$ \\
\hline Exclamation & $0.33 \pm 0.49$ & $1.83 \pm 1.47$ & $<0.01$ \\
\hline Opinion & $0.92 \pm 0.90$ & $1.67 \pm 1.44$ & $\mathrm{n} . \mathrm{s}$ \\
\hline Acknowledgement & $0.83 \pm 0.72$ & $1.67 \pm 1.61$ & $\mathrm{n} . \mathrm{s}$ \\
\hline Agreement & $0.42 \pm 0.79$ & $0.83 \pm 0.94$ & $\mathrm{n} . \mathrm{s}$ \\
\hline Total & $15.50+10.43$ & $21.17 \pm 9.62$ & $\mathrm{n} . \mathrm{s}$ \\
\hline
\end{tabular}

Table 6. Questionnaire results of participants' attitudes

\begin{tabular}{|l|c|c|c|}
\hline \multicolumn{1}{|c|}{ Question } & Chinese & Thais & p-value \\
\hline $\begin{array}{l}\text { Q1. If you know that you and others have different social } \\
\text { statuses, ways of your knowledge sharing will be different? }\end{array}$ & $4.17 \pm 0.72$ & $3.92 \pm 0.79$ & $\mathrm{n} . \mathrm{s}$ \\
\hline Q2. How much do you trust in others' knowledge? & $4.00 \pm 0.74$ & $4.17 \pm 0.39$ & $\mathrm{n} . \mathrm{s}$ \\
\hline Q3. How do you respect for others' knowledge? & $4.25 \pm 0.87$ & $4.33 \pm 0.65$ & $\mathrm{n} . \mathrm{s}$ \\
\hline $\begin{array}{l}\text { Q4. Sharing knowledge with others can make your ideas } \\
\text { increase more than individual thinking? }\end{array}$ & $4.50 \pm 0.67$ & $4.58 \pm 0.51$ & $\mathrm{n} . \mathrm{s}$ \\
\hline $\begin{array}{l}\text { Q5. Sharing knowledge with others can make your ideas } \\
\text { better than individual thinking? }\end{array}$ & $4.33 \pm 0.78$ & $4.17 \pm 0.72$ & $\mathrm{n} . \mathrm{s}$ \\
\hline $\begin{array}{l}\text { Q6. When you share knowledge with others, you expect that } \\
\text { you will receive useful knowledge from others? }\end{array}$ & $4.25 \pm 0.75$ & $3.83 \pm 0.72$ & $\mathrm{n} . \mathrm{s}$ \\
\hline $\begin{array}{l}\text { Q7. Would you try to persuade others to agree with your } \\
\text { thinking? }\end{array}$ & $4.00 \pm 0.85$ & $2.83 \pm 1.03$ & $<0.01$ \\
\hline
\end{tabular}

\subsection{Connections between Cultural Dimensions and Knowledge Sharing Patterns}

After analyzing discourses, we investigated how cultural differences influence Chinese and Thais to have the different patterns of online knowledge sharing. The cultural dimensions used in the analysis consist of power distance, individualism, masculinity, uncertainty avoidance, and long-term orientation. The connections between cultural dimensions and the patterns of online knowledge sharing are as follows.

\section{Power Distance}

The scores of 80 and 64 as shown in Figure 2 are evidence that China and Thailand are societies in which inequalities are accepted. We cannot find an explicit connection between this dimension and the patterns of online knowledge sharing. This is because the experiment was conducted as an online communication, not face-to-face 


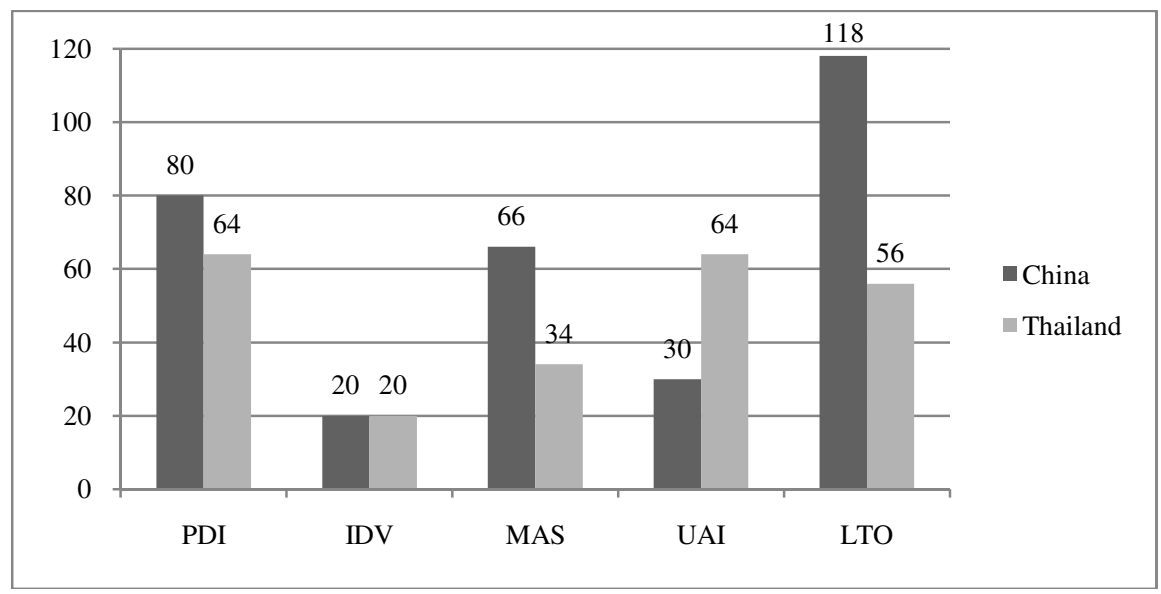

Fig. 2. Cultural Dimensions scores of China and Thailand [14]

communication and our participants did not know information about other participants. They did not have concerns about seniority, hierarchy, or authority when communicating with others online.

However, the result of Q1 from Table 6 reveals that if the participants (both Thai and Chinese) knew that they had different social statuses from one other, their patterns of online knowledge sharing would be different.

\section{Individualism}

The score of 20 on this dimension as displayed in Figure 2 shows that both China and Thailand are collectivist cultures that consider the group as the primary element. Communication between people in this culture is indirect. A society with a low score in this dimension has strong group cohesion and the priority of group goals is higher than individual goals. The harmony of the group has to be maintained and open conflicts are avoided. From the discourse analysis, it showed that both Thais and Chinese did not directly dispute others. They often expressed their ideas with opinions to avoid making someone to lose face. Moreover, they often used agreement discourses and acknowledgement discourses to represent their cooperation, modesty, and deference. The results of Q2-Q6 shown in Table 6 can support the connection between this dimension and patterns of online knowledge sharing. It shows that both Chinese and Thais have respect and trust for others in their own group/culture. Furthermore, it can represent a preference for group work.

\section{Masculinity}

In Figure 2, China scores 66 on this dimension and it can be considered a society that respects masculinity. The culture values competitiveness, assertiveness, ambition, and power. This society is success oriented and driven which can indicate that Chinese worried about their success in sharing knowledge. From Table 5, the Mann-Whitney $\mathrm{U}$ Test showed no significant difference between Chinese and Thais in the 
declaration. However, the number in the declaration category for Chinese accounted for 74.73 percent of total as displayed in Table 4. This indicated that the Chinese fully use their abilities in contributing their own knowledge. Moreover, the result of Q7 in Table 6 can support this analysis because Chinese tried to persuade others to agree with them to show their conviction.

With a score of 34, Thailand represents a society that values feminine characteristics. People in this society are less assertive and competitive. Moreover, this society shows for a preference for cooperation, modesty, and caring for others. Most of the Chinese expressions in the discussion were declarative sentences, whereas the Thais often used agreement sentences and acknowledgement sentences to represent their cooperation, modesty, and deference.

\section{Uncertainty Avoidance}

As shown in Figure 2, Thailand scores an intermediate 64 on this dimension; however, it is also indicating a slight preference for avoiding uncertainty. It means that Thais do not handle unexpected stories or events well. Thai participants felt doubtful during the online discussion because this experiment encouraged exchange of cultural knowledge that is different between each culture.

The statistical analysis using the Mann-Whitney $U$ Test revealed a significant difference between Chinese and Thais $(\mathrm{p}<0.01)$ in the number in the interrogation and exclamation categories. Thai participants expressed interrogative sentences more than Chinese did in order to reduce doubt and uncertainty during the knowledge-sharing process. Moreover, Thais often expressed exclamatory sentences more than Chinese did because of their amazement and doubtfulness in other expressions.

Compared with Thailand, China has a low score in this dimension (score $=30$ ). It can indicate that Chinese have high tolerance of deviant persons and ideas. The discourse analysis showed that Chinese seldom used interrogative sentences and exclamatory sentences compared to Thais. Moreover, this score suggests that the Chinese participants felt free to share knowledge and used informal language in expressing with others. According to discourse analysis, Chinese used expressions containing abbreviations, slang words, and symbols more than Thais in online exchanges. The number of those words from Chinese participants was twice the number of words from Thais.

\section{Long-Term Orientation}

Long-Term Orientation is the fifth dimension of Hofstede that was added after the original four to try to distinguish the difference in thinking between the East and West. For the dimension of long-term orientation, there were no good connections between online knowledge sharing patterns and this dimension because both Thailand and China are in the East.

Besides the cultural characteristics mentioned above, the style of communication can affect online knowledge sharing patterns. Based on Hall's concept of context, both Thais and Chinese have a high-context communication style. In the high-context 
style, people often use nonverbal elements such as voice tone, facial expression, gestures, and eye movement as parts of communication. Verbal message is indirect and implicit in this style [2]. Words and sentences may be collapsed and shortened. However, online communication requires characteristics of a low-context communication style that is direct and explicit because it is not a face-to-face communication and the nonverbal elements are more effective. Thus, online knowledge sharing between Thais and Chinese might face problems since they use fewer nonverbal elements to express themselves. Another problem is that Thais and Chinese might not be able to interpret symbolic language or abbreviations that are emerging in the present online culture (although they are familiar with indirect message). It leads to misunderstandings and negative feelings in communication. The other problem is that the high-context style is comfortable with a considerable amount of silence. People who are accustomed to utilizing the high-context style tend to leave a lot of space or dead air in conversation.

\section{$5 \quad$ Conclusions and Future Directions}

In this study, we explored the connections between cultural dimensions and online knowledge sharing patterns of users who have the high-context communication style. The laboratory experiment was conducted to collect discourses in the process of online knowledge sharing between Thais and Chinese. From the discourse analysis, we discovered that cultural differences can influence the way knowledge is contributed. The major cultural dimensions that influence Thais and Chinese to have the different patterns of online knowledge sharing are individualism, masculinity, and uncertainty avoidance. Our findings help to enhance intercultural communication competencies and improve understanding of the cultural variations. This can be fundamental for designing new tools for intercultural communication. Regarding future directions, we plan to resolve the following limitations.

- The current study focused on only two out of many world cultures and the significance of results might be limited due to the small number of participants.

- Since the study was a laboratory experiment, our participants were studying at graduate school in Japan, which is culturally diverse in some ways, but is relatively homogeneous in terms of age and occupation. Moreover, they have left their countries of origin more than a year ago and have absorbed other cultural characteristics from colleagues. This means they may not represent the larger population of Thais and Chinese. To address this limitation, we plan to extend this study by using a more diverse set of participants.

- Since authors cannot understand both Chinese language and Thai language, English was selected to be the common language in this study. To resolve this limitation, we plan to use native language as the common language and use some techniques of Natural Language Processing to support our study in the future. 


\section{References}

1. Alavi, M., Leidner, D.E.: Knowledge management systems: Issues, challenges, and benefits. Communication of the Association for Information Systems 1, 1-36 (1999)

2. Context of Cultures: High and Low, http: / / www2 .pacific.edu/sis/culture/pub/ Context_Cultures_High_and_Lo.htm

3. Fong, J., Burton, S.: A cross-cultural comparison of electronic word-of-mouth and country-of-origin effects. Journal of Business Research 61(3), 233-242 (2008)

4. Hara, N., Shachaf, P., Hew, K.F.: Cross-cultural analysis of the Wikipedia community. Journal of the American Society for Information Science and Technology 61(10), 20972108 (2010)

5. Hall, E.T.: Beyond Culture. Doubleday, New York (1976)

6. Hofstede, G., Hofstede, G.J., Minkov, M.: Cultures and Organizations: Software of the Mind, 3rd edn. McGraw-Hill, USA (2010)

7. Knutson, T.J., Komolsevin, R., Chatiketu, P., Smith, V.R.: A comparison of Thai and US American willingness to communicate. Journal of Intercultural Communication Research 31, 3-12 (2002)

8. Nguyen, T.D., Fussell, S.R.: How did you feel during our conversation? Retrospective analysis of intercultural and same-culture Instant Messaging conversations. In: Proceedings of the 2010 ACM Conference on Computer Supported Cooperative Work, pp. 117$126(2010)$

9. Pfeil, U., Zaphiris, P., Ang, C.S.: Cultural differences in collaborative authoring of Wikipedia. Journal of Computer-Mediated Communication 12(1), 88-113 (2006)

10. Pilhofer, K.: Cultural Knowledge: An Ethical Deconstruction of the Concept as a Foundation for Respect for Cultural Differences from a Post-Colonial and Levinasian Perspective. Master's Thesis, Copenhagen Business School (2010)

11. Setlock, L.D., Fussell, S.R.: What's it worth to you? The costs and affordances of CMC tools to Asian and American users. In: Proceedings of the 2010 ACM Conference on Computer Supported Cooperative Work, pp. 341-350 (2010)

12. Shu, W., Chuang, Y.: Why people share knowledge in virtual communities. Social Behavior and Personality 39(5), 671-690 (2010)

13. Siau, K., Erickson, J., Nah, F.F.H.: Effects of national culture on types of knowledge sharing in virtual communities. IEEE Transactions on Professional Communication 53(3), 278-292 (2010)

14. The Hofstede Centre, http: / / geert-hofstede.com/index.php

15. Williamson, D.: Forward from a critique of Hofstede's model of national culture. Human Relations 55(11), 1373-1395 (2002)

16. Wordpress.org, http://wordpress.org/

17. Yuizono, T., Li, W., Munemori, J.: Promoting Cultural Learning: Effects of Cultural Knowledge on Text Chats between Japanese and Chinese participants. In: König, A., Dengel, A., Hinkelmann, K., Kise, K., Howlett, R.J., Jain, L.C. (eds.) KES 2011, Part III. LNCS (LNAI), vol. 6883, pp. 167-176. Springer, Heidelberg (2011) 